\title{
Mapping Customers: A Case Study of a University Hospital in Indonesia
}

\author{
Purwaningsih', Nyoman Anita Damayanti' ${ }^{2}$, asronudin $^{3}$, Thini Nurul Rochmah ${ }^{2}$ \\ ${ }^{1}$ Doctoral Program of Public Health, Faculty of Public Health, ${ }^{2}$ Faculty of Public Health, \\ Universitas Airlangga, Mulyorejo, Surabaya, Indonesia
}

\begin{abstract}
Hospitals as health providers seek to understand the customers' needs concerning the healthcare services. The success of the hospital management depends on how the hospitals meet the customer's needs by understanding the situation and conditions of the customers, including knowing where the customer lives. This study aimed to obtain a geographical map of the hospital's customer's residencesbased on the subdistricts in Surabaya city. A formal survey method was employed by using the secondary data obtained from the Medical Record Unit of Airlangga University Hospital. The sample size of the data was 10\% of the number of patients from each year;2015, 2016, and 2017. Simple random sampling technique was employed by usingcomputer-generated selection. The data was entered into GIS mapping software. The results were shown in the form of a geographical map to observe the customer's distribution. The use of customer mapping is useful to support the leaders of the hospital management in making a business plan, including the expansion of the healthcare services offered and increasing the number of customers from other potential areas of residence.
\end{abstract}

Keywords: mapping, hospital customers, geographical information system, trade competition

\section{INTRODUCTION}

Healthcare service is one of the growing sectors in economy. Despite various negative opinions against free trade in healthcare, liberalisation in the health sector has enabled there to be consequences for national policy makers and health providers when it comes to meeting the population needs. ${ }^{1}$ To survive the trade and service competition, health service institutions should understand the customer's needs. Customers are central to the service business and should be involved in the production process. ${ }^{2}$ They have a crucial role in bridging with the providers so then the service product is known and accepted by the wider community. ${ }^{2}$ Likewise, hospital services also depend on the value of

\section{Corresponding Author:}

Purwaningsih

Doctoral Program of Public Health, Faculty of Public Health, Universitas Airlangga, Mulyorejo, Surabaya, Indonesia Email: purwaningsih@fkp.unair.ac.id the customers, both internal and external. In general, a customer as defined by the dictionary asa person or an entity who purchases goods or services produced or delivered by a business.

Despite the different conditions that sets them apart from other general customers, patients are the customers of a hospital or given health provider who receive the service after payment. By definition, apatient is a person receiving healthcare and medical treatment under a physician's supervision. ${ }^{3}$ Patients, as the hospital customers, are different from other business customers because of their diseases or injuries that make them vulnerable, afraid, pained, where they become drug dependence, feel fatigued and experience confusion. On the other hand, in certain circumstances,patients have to make complex decisions about life and death in a short period of time. Buying hospital services is intended to improve their health status. However, in some cases, the outcome of the service is uncertain due to multifactorial influences.

As a business entity and healthcare provider, the hospital should be able to provide the required treatment that is unique for each individual based on the diagnosis 
given by the physician. The service starts from the time of the patient's admission, throughout the hospital stay, until their discharge from the hospital. Providing satisfactory healthcare service to the patients leads to higher customer satisfaction which is associated with adherence to the medical treatment provided and the continuity of care. ${ }^{4}$ Therefore, understanding the customers' background and expectations is crucial for the hospital in order to meet their needs and to satisfy their patients. Mapping the patient's location of residence is one way to understand the customer's background. By mapping the patient's location, the hospital will find it easier to observe the distribution of customer territory based on theirreal situation on a local map. Social mapping is conducted to find information related to the sociodemographic characteristics in a specific area in order to support the decision-making process.

The use of social mapping in decision-making is beneficial to inform individuals of the current position of society and to plan what actions are required. Airlangga University Hospital is a public healthcare entity that provides secondary and tertiary levels of care, established in 2011. It is located at the heart of Surabaya city, the second largest city in Indonesia. The city population was nearly 2.95 million in $2015 .^{5}$ There are 59 hospitals and 103 specialist clinics that provide secondary and tertiary levels of healthcare. ${ }^{6}$ Since the implementation of the national health insurance (NHI) scheme in $2014^{7}$, other private and public hospitals also affiliate with the NHI agency in order to receive more patients. Other than that, all public and private hospitals are allowed to receive self-payment from patients. Although Airlangga Univeristy Hospital is a public entity with a non-profit orientation, the hospital should apply a strategic business plan to provide the customers with excellence and to improve the hospital business performance as indicated by an increased patient volume. Creating a social map of the hospital customers would help the hospital to plan health services that comply with the medical care standards as well as having a better customer orientation. Therefore, this paper aimed to describe the geographical distribution of the hospital's customers through the map-making process and its implications for hospital decision-making.

\section{METHOD}

The map-making process was done by using Geographical Information System (GIS) software.
The general purpose of mapping was to obtain a geographical description and to estimate the potential of the region. The hospital customer map allows for there to be observations of the patient volume from each subdistrict and the potential services offered by the hospital.

The process was initiated by collecting the secondary data of the patients admitted to Airlangga University Hospital between 2015-2017. The source of the data was the patient's medical records. We generated the data from $10 \%$ ofthe number of patients each year, with an equal composition of patients admitted to the emergency department, outpatient units and inpatient units. The data sampling was done through computerised simple random sampling. As not all ofthe patient's residence information containsazipcode, the data collected was based on the sub-districts within the administrative territory of Surabaya city.

\section{RESULTS AND DISCUSSION}

Surabaya city is administratively divided into 31 sub-districts with a total land area of 350.5 square kilometres. ${ }^{5}$ Airlangga University Hospital is located in Mulyorejo sub-district. In this study, we included the data of 5,647 patients admitted between 2015-2017. The details of the sample size from 2015 to 2017 were $795,1,735$, and 3,117 respectively. From this data, we observedaremarkable annual increase of patient volume by $218 \%$ in 2016 and $170 \%$ in 2017 . Overall, about $89 \%$ $(n=5,024)$ of the sample subjects were from Surabaya city, while $11 \%$ were patients from other cities.

The hospital customer mapsof 2015, 2016, and 2017 from Surabaya city were generated three maps. The legend on the right of the map presents the number of patients from each sub-district. We applied four scale categories based on the number of patients in each subdistrict in shades of grey colour, as follows:1)Very light grey: 0-50 patients; 2)Light grey: 51-150 patients; 3)Dark grey: 151-300 patients; 4 . Very dark grey: $>301$ patients.

From the first map, two sub-districts contributed 51-150 patients, while five sub-districts contributed 151-300 patients. The largest number of patients was contributed by Mulyorejo and Kenjeran sub-district. This map reflects that in 2015 the major customers of the hospital are the people living nearby to the hospital.

In the second map, there were 3 sub-districts that were light grey, 5 sub-districts that were dark grey, and 1 
sub-district that was very dark grey. The largest number of patients were from Mulyorejo sub-district and other nearby sub-districts. The increased number of patients from 2015 to 2016 seems to largely be from the same sub-districts near to the hospital. A significant increase in the number of patients was also observed from Rungkut sub-district.

As shown in the third map, there were 4 sub-districts that were dark grey and 3 sub-districts that were very dark grey. In 2017, most of the customers of the Airlangga University Hospital came from Tambaksari sub-district, Mulyorejo sub-district and Gubeng sub-district. These three sub-districts are among the sub-districts where there isahigh proportion of the population from the middle and upper level of income in Surabaya city. It reflects the increased acceptance of the hospital of patientsacross all levels of income, which in turn increases the market potential of Airlangga University Hospital.

As shown from the first to third map, the expansion of the utilisation of Airlangga University Hospital was represented by the increased number of patients annually.Within the area of 10 kilometres, there are 10 other government and private hospitals with a bed capacity ranging between 100-600. Most of the hospitals are teaching hospitals which have been operatingfor 5-30 years. As a business entity, Airlangga University Hospital is competing with those hospitals when it comes to providing a quality healthcare service, especially for the population of Surabaya city itself. In 2015-2016, the branding of Airlangga University Hospital targeted the lower and middle income population. It was expanded to target the upper income population as well in 2017.

According to McCarthyet al. (2016), the benefits of patient mapping are to support the planning of healthcare solutions by the multidisciplinary stakeholders in order to improve the hospital's performance and patient satisfaction, as well as to alleviate the current constraints in the healthcare service. ${ }^{8}$ Mapping involves a simple and appropriate visualisation of information that will help stakeholders to engage in the service, to collectively determine the objective and to monitor progress. ${ }^{9}$ Theresults of the customer mapping can be used by the executive board of Airlangga University Hospital as a tool to support the development of amarketing strategy plan. The hospital's marketing strategy is useful to determine the customer's needs, which can be implemented through three stages including the selection of customer targets, the identification of customer expectations and the decisions of the marketing strategies. Based on these strategies, Airlangga University Hospital could prepare specific facilities based on the needs or expectations of the targeted customers. In addition, the hospital also requires applying quality control with a competitive price, while providing a comfortable environment for the patients to improve their experience when using the services of the hospital.

\section{CONCLUSIONS}

Customer mapping is important to support the hospital management when developing a business strategic plan. The map contains the geographic distribution of hospital patients, which can visually inform the stakeholders of the situation and condition of the hospital customers. The map is useful to help develop marketing strategies with an ultimate goal to increase patient volume. From the maps generated from the medical record data of 20152017, the market share of Airlangga University Hospital has been expanded from the low and middle income communities to the upper income communities as well. From the customer mapping results, Airlangga University Hospital should continue improving their service quality, competitive pricing, and promoting the utilisation of the hospital services while providing a comfortable environment for a better customer experience. This can be achieved by improving the quality of the human resources, providing an efficient and effective care service, and setting a hospitality standard in addition to the standard operating procedures.

Ethical Clearance: Ethical approval was granted by the School of Public Health in Airlangga University, Surabaya.

Source of Funding: Self-funding.

\section{Conflict of Interest: Nil}

\section{REFERENCES}

1. Davis L, Erixon F. The health of nations: conceptualizing approaches to trade in health care. ECIPE Policy Brief; 2008.

2. Prahalad CK, Ramaswamy V. Co-creating unique value with customers. Strategy \& leadership. 2004;32(3):4-9. 
3. Deber RB, Kraetschmer N, Urowitz S, Sharpe N. Patient, consumer, client, or customer: what do people want to be called? Health Expectations. 2005;8(4):345-51.

4. Shirley ED, Sanders JO. Patient satisfaction: implications and predictors of success. JBJS. 2013;95(10):e69.

5. Government of Surabaya City. Rencana Pembangunan JangkaMenengah Daerah (RPJMD) Kota Surabaya 2016 - 2021. Surabaya2015.

6. Surabaya DHO. LaporanKinerjaTahun 2016 (The 2016 Performance Report). In: Surabaya DK, editor. Surabaya: DKK Surabaya; 2017.
7. Mboi N. Indonesia: On the Way to Universal Health Care. Health Systems \& Reform. 2015;1(2):91-7.

8. McCarthy S, O'Raghallaigh P, Woodworth S, Lim YL, Kenny LC, Adam F. An integrated patient journey mapping tool for embedding quality in healthcare service reform. Journal of Decision Systems. 2016;25(sup1):354-68.

9. Antonacci G, Reed JE, Lennox L, Barlow J. The use of process mapping in healthcare quality improvement projects. Health services management research. 2018;31(2):74-84. 